\title{
The Orthodox Church and the Mental Health Burden of a Pandemic: A Narrative Mini-Review
}

\section{Danny A. Schieffler Jr. ${ }^{1} \mathbb{D}$. Joshua Genig ${ }^{2}$}

Accepted: 26 June 2021 / Published online: 14 July 2021

(C) The Author(s), under exclusive licence to Springer Science+Business Media, LLC, part of Springer Nature 2021

\begin{abstract}
The mental health burden of the recent COVID19 pandemic will be extensive and pervasive likely for many years to come. The stress and anxiety of this event will undoubtedly impact Orthodox communities regardless of location after the world has met the crisis and resumed some sense of normalcy. The assessment of mental health needs among Orthodox Christians remains a largely unstudied phenomenon. A small narrative review was conducted to ascertain ways in which other faith-based organizations have studied mental health in their own communities. While studies that address many minority and immigrant-based faith-based organizations exist, these are limited in scope. Given similarities that exist between minority and immigrant-based faith-based populations and Orthodox communities, a planning framework is suggested to improve an Orthodox response post-pandemic.
\end{abstract}

Keywords Pandemic $\cdot$ Depression $\cdot$ Anxiety $\cdot$ Clergy training $\cdot$ COVID-19

\section{Introduction}

The COVID-19 global pandemic has changed how society lives. For Orthodox Christians around the world, this meant that the holiest days of 2020 (i.e., Great Lent, Holy Week, and Pascha) were celebrated online-a virtual reality of Holy Resurrection. The visceral reality of disease and death in centuries past was a much more familiar event than it has been in the modern age. The ways in which ancient people dealt mentally with these events, albeit common to all of the human race, have become somewhat obsolete. The Medieval physician, Tommaso del Garbo, for example, offered the following advice to those suffering during a plague: "Spend

Fr. Danny A. Schieffler Jr.

schiefflerd@sacredheart.edu

1 Sacred Heart University, 5151 Park Avenue, Fairfield, CT 06825, USA

2 St. Joseph Mercy Hospital, Ann Arbor, MI, USA 
your time in your house, but not with too many people, and at your leisure, in gardens" (Phillips, 2020).

Indeed, the advances of medicine have made many great plagues of the past nonconsequential, along with the ways in which society dealt with these mentally. We are now somewhat protected from the necessity of considering ways to survive physically and mentally when confronted with disease and death. In the midst of this reality have been the current "new norms" of working remotely, learning online, and socializing at a distance, among others. The profound impact upon the mental health of any society under these circumstances will likely have a lasting effect for years to come.

Fear, anxiety, and a general sense of uneasiness will make life, as we will now know it, seem more uncertain. Doubts and feelings of insecurity will take a toll on the psyche of many families. When such events impacted societies in ages past, the Church always provided comfort and hope (Walker et al., 1985). Opening Churches in disaster areas, providing shelter for refugees and the disease, and establishing houses of care, among other programs, have been a part of the Christian organizational experience (Walker et al., 1985). Plagues, wars, and revolutions have come and gone but the Church remains. Yet, this places before us a fundamental question at this time: is the Church ready to meet this new challenge? Given the many ways that life continues to change as a result of the pandemic and the mental health impact likely to follow, are we prepared to address what may come in the modern context?

\section{Methodology}

Peer-reviewed analysis of the mental health needs specifically of Orthodox Christians is largely absent in the body of literature dedicated to mental health and faithbased organizations. Although studies in traditionally Orthodox countries such as Georgia and Romania do exist, their application to the American experience is questionable but not altogether irrelevant (Cuceu \& Pontikes, 2016; Giorgadze et al., 2017). A EBSCO Discovery Service, ProQuest, and JSTOR data search were performed cross-referencing mental health and faith-based organizations. Articles referencing health services outside of mental health in faith-based communities were eliminated as well as those over 15 years old. The articles that were retained each addressed aspect of immigrant and minority groups which closely resembles the experience of Orthodox Christians in the USA given the ethnic preferences and insularity of many parishes.

\section{Orthodox Psychology}

The mental health of Orthodox Christians and, indeed, many faith-based communities, remains a largely understudied phenomenon, although the potential positive benefits have been explored (CMHS, 2004; Hankerson \& Weissman, 2012; Kramer, 2010). Explorations into the subject of mental health stigma in immigrant 
and minority-based faith-based populations, of which many Orthodox communities consist, have also shown pervasive suspicion and misunderstanding of mental health treatment. (Caplan, 2006; Codjoe et al., 2019; Hankerson \& Weissman, 2012). In Caplan's work, for instance, the impact of stigma is directly targeted in three largely Latino Churches. Although small in scale and limited to one particular ethnic group, this work shows the impact that stigma has in these congregations and how that impedes mental health treatment acquisition (Caplan, 2006). Given that many Orthodox congregations are also composed of immigrant populations, the cultural implications might be generalized given the conservative and religious fervor within these groups. Hankerson and Weissman conducted a meta-analysis of church-based programs focusing on African-American congregants. They determined that while Church-based programs help with racial disparities in health service access, the focus on mental health programs is "extremely limited" (Hankerson \& Weissman, 2012). Issues of individuals being “...ostracised or isolated...” were also noted in Codjoe and colleagues' work. This was particularly noted among historically black Churches in the UK but could easily apply to other communities as well (Codjoe et al., 2019).

Suspicion among faith-based communities toward organized mental health services often are found to center around not only the perceived weaknesses of religious faith, but also the general secular institutional nature of professional mental health treatment. Theological explanations (and perhaps sometimes justifications) made concerns about assessment of mental health burden in some congregations seem unnecessary (Leavey et al., 2007). In other words, since the emotional aspects of handling crises are seen solely as subjective, it is not necessary to assess these aspects since religious belief should suffice if faith is perceived as strong.

Nevertheless, the mental health impact of these recent global events cannot be so easily underestimated, especially in a secular world where so many options are available to process these emotions outside of faith-based organizations. Clergy, who may or may not be trained in mental health assessment, must necessarily consider other options for more heavily impacted individuals of which traditional, spiritual counseling may not be all inclusive or, in fact, helpful.

Through individual counseling and pastoral care, many clergy are well aware of the issues with which some of their congregants struggle (Dalencour et al., 2017). Given the protected nature of that relationship, mental health services beyond the Church may or may not be initiated. Some faith-based organizations have liaison with mental health practitioners and public health services to address these perceived gaps (Codjoe et al., 2019; Williams et al., 2014). For instance, Laverne Williams and colleagues recognized many ways in which social workers were working with faith-based organizations toward the goal of health promotion. What they found, however, was that focus on specific mental health issues, such as major depression, was not present in the body of literature related to that relationship. As such, they recommend the establishment of a "mental health ministry" that specifically addresses the exposure of African-American communities to mental health studies in their work (Williams et al., 2014). It should be noted that many Orthodox communities offer meeting space for Alcoholics Anonymous meetings and other 12 -step programs currently. These are not often accessed by members of the specific 
congregations, however. These groups could provide a platform for greater outreach if promoted from within the Church.

The literature notes that those mental health programs that do exist tend to be directed at minority individuals where the local Church plays a vital role in community engagement and where other linkages to services may not be as readily accessible (Codjoe et al., 2019). This type of relationship allows for better communication between organizations and churches with the express intent of improving access and outcomes to a broad range of social services that may or may not be directly associated with mental health. However, as Kramer points out, many Churches may be limited in terms of resources to support those linkages in communities especially where public funds are involved with mental health programs (Kramer, 2010). There may be further complications related to these limitations such as "...religious content, separation, and client protections..." which may or may not cross the boundaries of Priest/Parishioner confidentiality (Kramer, 2010). This model redirects the mental health needs of the parishioners into existing public health systems with the Church as the linkage (DeKraal et al., 2011). The advantage of this model is the willingness of the individuals to participate given their preexisting relationships with the Church. (Williams et al., 2014).

These partnerships, while positive, can sometimes blur the boundaries between the various domains of mental, physical, and spiritual health when only viewed fragmentally (Leavey, et al., 2007; Loue, 2010). In an extensive exposé, Loue describes the legal and ethical dilemmas that can sometimes arise when the lines of mental health and spiritual experience interconnect. Using a series of case examples, this author points out the conflicts that may arise with issues such as sexual identity or the role of "faith healing" in relation to mental health concerns. The legal responsibility of clerical counseling and pastoral guidance has been adjudicated in courts of law (Loue, 2010). Thus, the need for clergy to be familiar with services outside the Church could be argued as a tool to decrease parish liability.

Turning again to the UK, Leavy and colleagues attempted a qualitative analysis of clergy opinions in relation to mental health care in the context of their congregations. "Thirty-two interviews were completed in a sample that contained 19 Christian ministers, six rabbis and seven imams." (Leavey et al., 2007). Their exploration concluded that clergy do recognize the burden of mental health issues among their congregants. However, clergy did not always feel trained in those issues adequately enough to address the myriad of interpersonal and functional issues that mental health can impact. Thus, the need for "collaboration" between religious groups and mental health services is seen as a necessary bridge to effectively address the gaps that clergy training may have not provided. They also note that the role of clergy in the lives of many people is not well understood or appreciated by the mental health professionals. For instance, spiritual direction as a means of helping with anxiety over life issues through greater contact with a "higher power" is viewed with suspicion even while it is a hallmark of most 12-step programs. The religious emphasis, however, is not always appreciated in the mental health community. This, too, in their analysis would need to be corrected to "....accommodate spiritual conceptualizations of illness" into the framework of mental health support. (Leavey et al., 2007). 
The foregoing assumes, however, that clergy are trained to address (or at least recognize) mental health issues from both the physiological and theological viewpoints. Wong and colleagues analyzed the results from the 2012 National Congregations Study. This analysis seeks to "... estimate the percentage of congregations providing programs to support people with mental illness and to identify internal and external factors associated with congregations' sponsorship of mental health programming" (Wong et al., 2018). Their results demonstrate that a congregation's ability to support social services that address mental health is related to the general financial and overall resources available to those congregations (Wong et al., 2018). The direct impact of individual clergy, however, was only mitigated in terms of age and experience and not necessarily a function of training directly. While many Orthodox communities do not have large financial or capital resources, clergy training and exposure to local services could fill this gap.

Seeing one's mental health as merely a function of the strength of one's faith might necessarily lead to an even greater burden (Leavey et al., 2007). This includes, of course, the mental health of clergy themselves. Indeed, great care must be taken so that clergy are trained in mental health dynamics to avoid unnecessary stress on the part of both them and their congregations. To that end, what is the answer given the current environment?

The Church is an archetype "hospital" where people come to seek healing of both soul and body. It is a place of repair (Alfeyev, 2017). As such, the Church cannot ignore modern approaches to mental well-being. The secular world is too saturated with those approaches to be disregarded, especially in the current climate; professional approaches must at least be addressed. Yet, the time-tested approaches of the Church must also not be ignored or regulated only to the past.

What is eternal is always contemporary. Resources for the contemporary applicability of these ancient approaches include Larchet's seminal work, The Theology of Illness (2002). Here, Larchet puts care for humans in its proper perspective, namely that "everything that involves the body involves the person as a whole." Another helpful contemporary Orthodox work, Suffering and the Nature of Healing (Hinshaw, 2013), puts suffering itself-whether physical or psychological—in its proper perspective, namely as something that has the potential to be transformed into victory. In short, this suffering that we have endured these last several months does not have to be a defeat but, by the mercy of God, can be changed into a cause for transformation. Of particular value is that, while these approaches may be contemporary, they call upon the tested methods of Orthodox Christians who have come and gone. Though situations have changed over the long course of this world's history, human emotions have not changed. However, because approaches to those emotions have been modified over the centuries, it is important for the Orthodox Church and Orthodox Christians to apply the wisdom of the past to new situations in the present with greater fervor and specificity.

The weaknesses of some faith-based organizations to adequately address mental health issues is not unknown, so any and all tools needed to correct that should be accessed and evaluated based on that community's needs and resources (Kopacz et al., 2019). Through the use of a survey, Kopacz and colleagues sought to understand the differences in support given the veteran populations 
in faith-based organizations compared to non-faith-based. What they found is that "... faith-based respondants were found to provide significantly less mental health, suicide prevention, education/outreach, and other services" to veteran populations (Kopacz et al., 2019). Their work recommends linkages between faith-based organizations and local agencies to fill this service gap (Kopacz et al., 2019). The potential to mediate that impact has also been recognized and actively encouraged. (Leavey et al., 2007). Thus, clergy play a vital, central role in the mitigation of the eventual impact. The tensions that often arise, however, between the mental health world and the religious community must be recognized as well. Centuries of misunderstandings and mistrust between the two groups are a reality that needs to be addressed at the individual level. Sullivan and colleagues make it clear that these historical prejudices have their impact but are not insurmountable (Sullivan et al., 2014). Their examination of a VA population demonstrated that cooperation can provide much needed support across a spectrum of both mental and spiritual adversities. They recommend greater partnerships so that mental health professionals and clergy can gain a better understanding of each other and how they can complement the work of the other in the mental healing process (Sullivan et al., 2014). A failure to properly prepare for the inevitable impact of the pandemic is pastorally irresponsible and, at the same time, very amenable given what has already been studied.

\section{Discussion}

At the writing of this article, many Churches still remain limited to the public. Now is the time for clergy to prepare for the likely negative impact and fallout the post-COVID environment will have on their congregations. The resources mentioned in this work can be used to strategically initiate a plan of intervention that must necessarily be multidimensional. These interventions could include outreach to local mental health organizations, parish discussions on mental health concerns, joint programs with local agencies and groups and others mentioned above. This includes better familiarity of the clergy with not only the work that these groups do but also research into their own traditions of health and how this might be applicable.

The mental recovery of Orthodox Christians requires strategic planning beyond waiting for the Churches to fully reopen. As mentioned in several works, clergy should investigate mental health resources in their communities. Whether secular or faith based, many services available take time to explore and monitor for appropriateness. Referring congregants to services implies approval, so care must be taken to prevent confusion and misunderstanding. Clergy should also assess their own understanding of mental health treatment and familiarize themselves with the various modalities employed, especially related to incidents of major societal disruption. This assessment will help to allay any fears or misgivings that may arise. Finally, and most importantly, clergy should care for themselves. Clergy have been impacted by the same stressors that all society has in these days. Family issues, income, and 
quarantine living have undoubtedly taken their toll. This will impact the already difficult ministry of clergy if it is not recognized and addressed.

\section{Conclusion}

The ability of the Orthodox Church to handle the recent pandemic, as is often the case, depends on its people. The ability that Orthodox Christians have to support and care for each other in a crisis has been proven historically many times and in many contexts (Walker et al., 1985). Now is the time to engage that spirit. What this limited exploration demonstrates is that there are resources available for Church leadership if that leadership takes the time to explore those options. Whether it is through local partnerships or internal organizations, the Church can play a sizable and dramatic role in the recovery of its people from the mental health burden of recent events. Now is the time to strategically plan for that recuperation and healing.

\section{Declarations}

Conflict of interest The authors declare that they have no conflict of interest.

Human and Animal Rights This chapter does not contain any studies with human participants or animals performed by any of the authors.

Informed Consent for this type of study formal consent is not required.

\section{References}

Alfeyev, H. (2017). Orthodox Christianity: Volume II doctrine and teaching of the orthodox church. Yonkers, NY: St Vladimir's Seminary Press.

Building bridges: Mental health consumers and members of faith-based and community organizations in dialogue. (2004). Rockville, MD : U.S. Dept. of Health and Human Services, Substance Abuse and Mental Health Services Administration, Center for Mental Health Services, 2004.

Caplan, S. (2006). A pilot study of a novel method of measuring stigma about depression developed for Latinos in the faith-based setting. Community Mental Health Journal, 52, 701-709.

Codjoe, L., Barbar, S., \& Thonricroft, G. (2019). Tackling inequalities: A partnership between mental health services and black faith communities. Journal of Mental Health, 28(3), 225-228.

Cuceu, M., \& Pontikes, T. (2016). The physician and community of faithful in the integrated care of the mentally ill: An orthodox Christian discussion of the physician's moral and professional obligations. Christian Bioethics: Non-Ecumenical Studies in Medical Morality, 22(3), 301-314.

Dalencour, M., Wong, E. C., Tang, L., Dixon, E., Lucas-Wright, A., Wells, K., \& Miranda, J. (2017). The role of faith-based organizations in the depression care of African Americans and Hispanics in Los Angeles. Psychiatric Services, 68(4), 368.

DeKraal, M. B., Bulling, D. J., Shank, N., \& Tomkins, A. J. (2011). Faith-based organizations in a system of behavioral health care. Journal of Psychology \& Theology, 39(3), 255-267.

Giorgadze, K., Shengelia, R., \& Durglishvili, N. (2017). Impact of orthodox Christian faith and spirituality on society's mental health (Based on the Population Survey of Tbilisi, Georgia). Georgian Medical News, 271, 76-85. 
Hankerson, S. H., \& Weissman, M. M. (2012). Church-based health programs for mental disorders among African American: A review. Psychiatric Services, 63(3), 243-249.

Hinshaw, D. B. (2013). Suffering and the nature of healing. St. Vladimir's Seminary Press.

Kopacz, M. S., Dillard, S. B., Drame, E. F., \& Quigley, K. S. (2019). Faith-based groups as a bridge to the community for military veterans: Preliminary findings and lessons learned in online surveying. Journal of Religion and Health, 58, 236-245.

Kramer, F. D. (2010). The role for public funding of faith-based organizations delivering behavioral health services: Guideposts for monitoring and evaluation. American Journal of Community Psychology, 46(3-4), 342-360.

Larchet, J. C. (2002). The theology of Illness. St. Vladimir's Seminary Press.

Leavey, G., Lowenthal, K., \& King, M. (2007). Challenges to sanctuary: The clergy as a source for mental health care in the community. Social Science \& Medicine, 65, 548-559.

Loue, S. (2010). Faith-based mental health treatment of minors. A call for legislative reform. Journal of Legal Medicine, 31, 171-201.

Phillips, J. (2020). Medieval Wisdom for Mental Health in COVID-19. Dec. 2020. Retreived from https:// marginalia.lareviewofbooks.org/medieval-wisdom-for-mental-health-in-covid-19/.

Sullivan, S., Pyne, J. M., Cheney, A. M., Hunt, J., Haynes, T. F., \& Sullivan, G. (2014). The per versus the couch: Relationship between mental health and faith communities and lessons learned from a VA/Clergy partnership project. Journal of Religion and Health, 53, 1267-1282.

Walker, W., Norris, R. A., Lotz, D. W., \& Handy, R. T. (1985). A history of the Christian church (4th ed.). New York, NY: Charles Scribner's Sons.

Williams, L., Goorman, R., \& Hankerson, S. (2014). Implementing a mental health ministry committee in faith-based organizations: The promoting emotional wellness and spirituality program. Social Work in Health Care, 53, 414-434.

Wong, E. C., Fulton, B. R., \& Derose, K. P. (2018). Prevalence and predictors of mental health programming among US religious congregations. Psychiatric Services, 69(2), 154-160.

Publisher's Note Springer Nature remains neutral with regard to jurisdictional claims in published maps and institutional affiliations. 